Article

\title{
Deformation and Cracking Mechanism in CrN/TiN Multilayer Coatings
}

\author{
Ahmad Azizpour 1,2,*, Rainer Hahn 2 ${ }^{-1}$, Fedor F. Klimashin ${ }^{2}{ }^{(0)}$, Tomasz Wojcik ${ }^{2}$, \\ Esmaeil Poursaeidi ${ }^{1}$ and Paul Heinz Mayrhofer ${ }^{2}$ (D) \\ 1 Department of Mechanical Engineering, Faculty of Engineering, University of Zanjan, University Boulevard, \\ Zanjan 45371-38791, Iran; epsaeidi@znu.ac.ir \\ 2 Institute of Materials Science and Technology, TU Wien, 1060 Vienna, Austria; rainer.hahn@tuwien.ac.at (R.H.); \\ fedor.klimashin@outlook.com (F.F.K.); tomasz.wojcik@tuwien.ac.at (T.W.); \\ paul.mayrhofer@tuwien.ac.at (P.H.M.) \\ * Correspondence: ahmad_azizpour@znu.ac.ir
}

Received: 10 May 2019; Accepted: 30 May 2019; Published: 1 June 2019

check for updates

\begin{abstract}
In this study, the effects of the microstructural properties on the deformation and damage mechanism of $\mathrm{CrN} / \mathrm{TiN}$ multilayer coatings deposited on Custom 450 steel using the unbalanced reactive magnetron sputtering PVD process were studied. All coatings were fabricated with an overall thickness of $1.5 \mu \mathrm{m}$, but different bilayer periods $(\Lambda)$. Structural and mechanical properties of coatings were investigated by XRD analysis and nanoindentation experiment, respectively. Indentation tests at three loads of 100,300 , and $450 \mathrm{mN}$ were performed on the coatings' surface and then, cross-sections of fractured imprints were analyzed with SEM and TEM. Measuring the length of the cracks induced by indentation loads and analyzing the load-displacement curves, apparent fracture energy values of multilayer coatings were calculated. We observed that multilayer systems with bilayer periods of 4.5-15 nm possess superlattice structure, which also results in higher values for Young's modulus and hardness as well as higher fracture energy. Comparison of cross-sectional SEM and TEM observations showed that coatings with smaller bilayer periods tend to deform by shear sliding mechanism due to the existence of the long-grown columns, while short dispersed grains-growing in the coatings with a larger bilayer period-led to deformation via local grain boundary sliding and grain rotation.
\end{abstract}

Keywords: CrN/TiN multilayer coatings; superlattices; cross-sectional SEM and TEM analysis; deformation mechanism; fracture energy

\section{Introduction}

Gas turbine compressors are prone to performance losses because of erosion of the compressor blades when being operated in regions with a dusty and sandy atmosphere and when sand, fly ash, salt, and ice crystals or volcanic ashes are ingested. The fabrication of the protective coatings by various deposition methods allows solving such problems in industrial applications to improve wear and corrosion resistance and, particularly, prevent compressor blades from premature loss of material. A wide variety of multilayer coatings comprising transition metal nitride layers such as TiN, $\mathrm{CrN}, \mathrm{TaN}, \mathrm{MoN}$, and VN have been extensively studied due to their promising properties as high hardness, high melting temperatures, and good chemical and physical stability [1-8]. Amongst different transition metal layer combinations, $\mathrm{CrN} / \mathrm{TiN}$ multilayer coatings have attracted great attention on the interrelation among their microstructure, morphology, and resulting mechanical properties [4,9-17].

Significant enhancement in measured hardness values was achieved by growing the films in a nanolayered architecture, referred to as superlattice films. Thereby the bilayer period-the thickness of two repeating layers-is in the nanometer range $[17,18]$. Beside the increasing demand to improve 
the coatings deformation strength through the hardness enhancement, a sufficiently high cracking resistance defined as fracture toughness is also requested to sustain the coatings and underlying materials integrity against abrupt rupture of the system. Usually, hardness and toughness are related inversely together, and a compromise needs to be reached [19-22]. Nevertheless, multi-layering is known to improve both hardness and toughness by means of different mechanisms like threading dislocations to individual layers by interfaces, generalized Hall-Petch-like effect and multitude of internal interfaces causing crack deflections at interfaces [23,24]. By employing in-situ micromechanical cantilever bending tests on free-standing TiN/CrN superlattice films, simultaneous increase in both fracture toughness and hardness peaking at similar bilayer period was reported by Hahn et al. [17].

Although numerous studies report on the enhanced mechanical properties of $\mathrm{CrN} / \mathrm{TiN}$ multilayer coatings, only a few works dealt with deformation behavior investigation of nitride multilayer coatings $[10,25]$. Since some films produced by physical vapor deposition like TiN tend to exhibit columnar grain structures, inter-granular shear sliding is supposed to improve the damage resistance of coatings [26]. Nanoscratch experiments performed on CrN/AlN nanolaminate coatings with constant bilayer period followed by cross-sectional scanning electron microscopy (SEM) and transmission electron microscopy (TEM) showed that plastic deformation is mainly due to the grain rotation for nanocrystals and grain boundary sliding (GBS) for larger grains $[25,27]$. However, effects of different bilayer periods on the deformation mechanisms as well as toughness have not been considered in these studies. Based on the complex nature of toughness measurements in scratch tests, indentation experiment is a more useful characterization method which can give better measuring tools to determine the apparent fracture toughness regarding the induced cracks and better understanding of the deformation events inside the coating through cross-sectional SEM and TEM analyses. Fracture modes affecting thin films and coatings of various materials have been extensively studied using indentation; generally, three types of fracture can be observed: radial cracks that initiate on the median planes, near-contact Hertzian cone fractures, and circumferential ring cracks that initiate well outside the contact [28]. Therefore, based on the generated cracks, relevant approaches are used to calculate the apparent fracture toughness.

In the present study, CrN/TiN multilayered coatings with bilayer periods in the range of $1.5-1500 \mathrm{~nm}$ were deposited on the Custom 450 steel by an unbalanced reactive magnetron sputtering process. The chosen isostructural system (forming a solid solution and indicating potential coherent growth) shows a difference in lattice constants of $\sim 0.1 \AA$ (4.2417 $\AA$ (ICDD 00-038-1420) and $4.144 \AA$ (ICDD 01-083-5612) for TiN and CrN respectively). This leads to potential coherency stresses-in the case of an ideal interface- of -5.0 and 3.7 GPa for TiN and $\mathrm{CrN}$, respectively, in addition to growth-related and thermal stresses. An interface width of one unit cell (due to interdiffusion) consequently reduces these stresses by half to -2.5 and $1.8 \mathrm{GPa}$. Structural and mechanical properties were investigated using XRD and nanoindentation, respectively. Additionally, indentation experiments were performed on all multilayers to compare the coatings' response to deformation induced by cracking mechanism. Considering the generated cracks and analyzing the load-displacement curves, dissipated energy values were calculated. Failure mechanisms were also analyzed using cross-sectional SEM and TEM observations. Special attention was paid to the deformation features and crack paths and their interaction with microstructure and layers configuration, interlayers or coating-substrate interface.

\section{Materials and Methods}

The CrN/TiN multilayer coatings were deposited on Custom 450 steel, which is a tempered martensitic stainless steel frequently used in, e.g., axial compressor blades. The substrates were prepared in mirror polished sheets with the dimensions of $20 \times 7 \times 1.5 \mathrm{~mm}^{3}$. Prior to the deposition, the substrates were ultrasonically cleaned in acetone and ethanol, mounted inside the chamber and thermally cleaned for $20 \mathrm{~min}$ (at $300{ }^{\circ} \mathrm{C}$ ). In order to further cleaning of substrates, by applying a voltage of $-750 \mathrm{~V}$ and using $\mathrm{Ar}^{+}$ions, plasma etching was performed for $10 \mathrm{~min}$ at a total pressure of 6 Pa. Using unbalanced reactive magnetron sputtering PVD method with an AJA Orion 5 lab-scaled 
machine (AJA International, Scituate, MA, USA), deposition process in the chamber equipped with a three-inch Ti (grade 2) and a two-inch Cr target with purity of $99.6 \%$ for both was carried out. Argon $(\mathrm{Ar})$ and nitrogen $\left(\mathrm{N}_{2}\right)$ were used as process and reactive gases, respectively.

The layers' deposition was carried out at a substrate temperature of $300{ }^{\circ} \mathrm{C}$ with a total pressure of $0.4 \mathrm{~Pa}$ and a bias voltage of $-60 \mathrm{~V}$ (using a DC power supply) applied to the rotating substrates. The process parameters are listed in Table 1. With the same parameters but different bilayer periods, different $\mathrm{CrN} / \mathrm{TiN}$ multilayer systems were deposited with equal total thickness using a computer-controlled shutter system. All of $\mathrm{CrN} / \mathrm{TiN}$ multilayer systems were designed to have a nearly equal thickness (about $1.5 \mu \mathrm{m}$ ) and bilayer periods, $\Lambda$, of 1.5, 4.5, 7.5, 15, 37.5, 150, 375, 750, and $1500 \mathrm{~nm}$ (symmetrically composed of TiN and CrN layers).

Table 1. Deposition parameters for CrN/TiN multilayers.

\begin{tabular}{ccc}
\hline Process Parameter & Unit & Value \\
\hline Average deposition time & $\mathrm{min}$ & 220 \\
Deposition temperature & ${ }^{\circ} \mathrm{C}$ & 300 \\
Argon flux & $\mathrm{sccm}$ & 5 \\
Nitrogen flux & $\mathrm{sccm}$ & 5 \\
Total pressure & $\mathrm{Pa}$ & 0.4 \\
Ti cathode current & $\mathrm{mA}$ & 1000 \\
Cr cathode current & $\mathrm{mA}$ & 600 \\
Bias voltage & $\mathrm{V}$ & -60 \\
\hline
\end{tabular}

In order to evaluate the morphology and thickness of coatings, pictures of cross sections were taken using secondary electron (SE) detector in a FEI Quanta 200 FEGSEM scanning electron microscope (Hillsboro, OR, USA). Energy dispersive X-ray spectroscopy (EDX), calibrated using SECS Light-element Calibration Standard CrN (Ardennes Analytique SPRL), was used for chemical investigations of the coatings. Phase composition was analyzed by means of X-ray diffraction (XRD). In symmetric Bragg-Brentano geometry, the X-ray diffraction patterns were collected using a PANalytical XPert Pro MPD ( $\theta-\theta$ diffractometer, Malvern Panalytical, Malvern, UK) equipped with a $\mathrm{Cu} \mathrm{K} \alpha \mathrm{X}$-ray radiation source $(\lambda=1.5406 \AA)$.

For evaluating the hardness and Young's modulus, nanoindentation experiments were carried out on coatings using a Fischer Cripps ultra-micro indentation system (UMIS) equipped with a Berkovich diamond tip. The nanoindentation tests were carried out by performing 31 indents on each coating with different loads. Indentation hardness, $H$, and modulus, $E$, were obtained by evaluating the unloading parts of the load-displacement curves after Oliver and Pharr [29] and assuming the Poisson's ratio to be 0.25. A detailed description of the evaluation process of the film-only values as well as the information on the accuracy of the measurements and indentation equipment is given in References [30-32].

In order to investigate the fracture phenomena, sufficiently high loads have to be applied. Utilizing UMIS equipped with a cube-corner diamond tip, indentation tests were performed at 100, 300 , and $450 \mathrm{mN}$ (five indents at each load). By analyzing discontinuities in the loading parts of the load-displacement curves and using energy method suggested by Chen et al. [33], fracture energy was determined.

After the investigations of the fracture surfaces by SEM, in order to explore the cracks inside the coating (especially beneath the indent region) as well as the mechanism of plastic deformation of the CrN/TiN multilayers, TEM and scanning TEM (STEM) analyses were performed on a FEI TECNAI F20 device, equipped with a field emission gun and operated at $200 \mathrm{kV}$ acceleration voltage. For this purpose, electron transparent cross-sectional samples were prepared across the diagonal of imprints by means of focused ion beam (FIB) technique with $\mathrm{Ga}^{+}$ions. To prevent damage to the sample, $\mathrm{CrN} / \mathrm{TiN}$ multilayers were coated with a thin layer of platinum (Pt) before FIB-preparation. The latter was carried out by using a stepwise milling starting with an acceleration voltage of $30 \mathrm{kV}$ and milling 
current of $5 \mathrm{nA}$, which was subsequently reduced to $0.1 \mathrm{nA}$ for final milling. All STEM micrographs were taken using a high-angle annular dark field (HAADF) detector for mass contrast.

\section{Results and Discussion}

\subsection{Coating Morphology and Structure}

Cross-sectional morphology of films and their multilayer structure were studied by SEM analysis. Figure 1 shows selected images of the TiN/CrN multilayer with the bilayer periods of $4.5 \mathrm{~nm}$ (a) and $150 \mathrm{~nm}(\mathrm{~b})$ and nearly equal total thicknesses of about $1.5 \mu \mathrm{m}$. Due to the extremely small layer thickness in the multilayer coating with $\Lambda=4.5 \mathrm{~nm}$, layer arrangements cannot be observed in SEM image of Figure 1a. Therefore, an inset picture (placed in the top right side of Figure 1a) taken by TEM is used to demonstrate the layered structure. Meanwhile, multilayer structure of the coating with $\Lambda=150 \mathrm{~nm}$ can easily be seen in SEM image of Figure $1 \mathrm{~b}$, in which bright and dark areas represent $\mathrm{CrN}$ and TiN layers, respectively. Due to different rates of cathode evaporation and nitride formation, TiN layers are slightly thicker than $\mathrm{CrN}$ layers, which is more evident in the samples with larger bilayer periods.

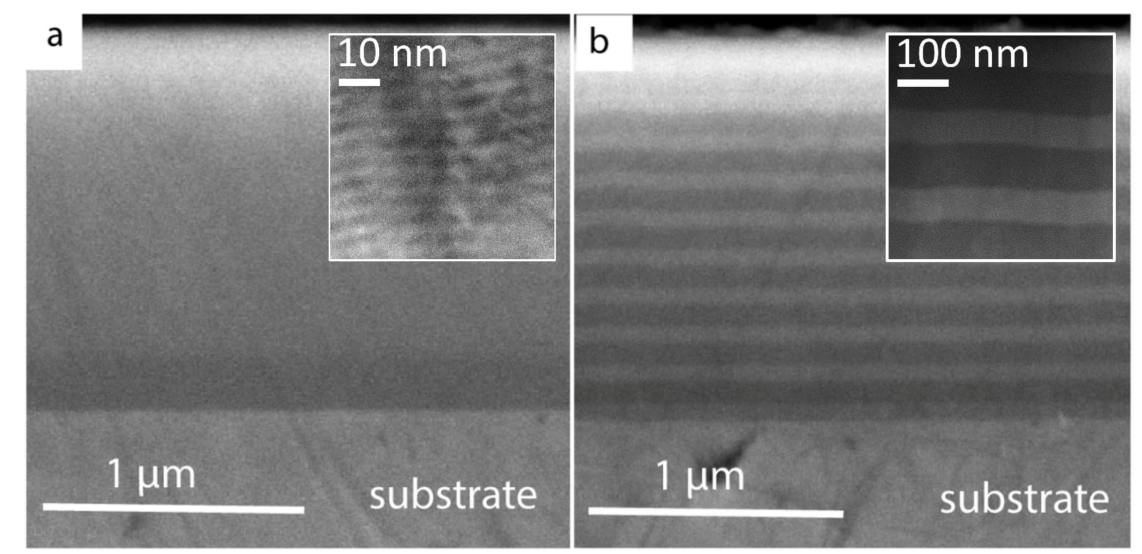

Figure 1. Secondary electron scanning electron microscopy (SEM) image of polished cross-sections of $\mathrm{CrN} / \mathrm{TiN}$ multilayer coatings with bilayer periods of (a) $4.5 \mathrm{~nm}$ and (b) $150 \mathrm{~nm}$. The insets show TEM images of those coatings.

Structural investigation of multilayers was carried out with XRD analysis and patterns are presented in Figure 2. An XRD pattern of Custom 450 steel is included as the bottom graph in Figure 2, in order to highlight the $2 \theta$ position of the substrate reflections in the XRD patterns of our CrN/TiN multilayers. In addition, XRD patterns of our monolithic $\mathrm{CrN}$ and TiN films allow one to track the peak shift (the observed main peak (220) for $\mathrm{CrN}$ is not shown here). The XRD patterns of CrN/TiN multilayer coatings with increasing bilayer period are arranged from bottom to top. All of the thin films reveal a face-centered cubic (c) structure with highly oriented (111) growth. Due to the presence of compressive residual stress in PVD coatings caused by thermal expansion coefficient difference between metallic substrate and ceramic layers, cumulative main peaks have shifted towards lower $2 \theta$ values as compared to diffraction patterns acquired from the (stress-free) powders of c-TiN (ICDD 00-038-1420) and c-CrN (ICDD 01-083-5612). Coatings with bilayer periods of 4.5, 7.5, and $15 \mathrm{~nm}$ show negative and positive satellite peaks being indicative of a superlattice structure. The superlattice structure cannot be observed for the films with bilayer period of $1.5 \mathrm{~nm}$, when a solid solution of c-TiN and c-CrN is assumed to form, and exceeding $37.5 \mathrm{~nm}$, when c-TiN and c-CrN layers are much less mutually affected as reflected in clearly separated (111) reflections, see Figure 2. 


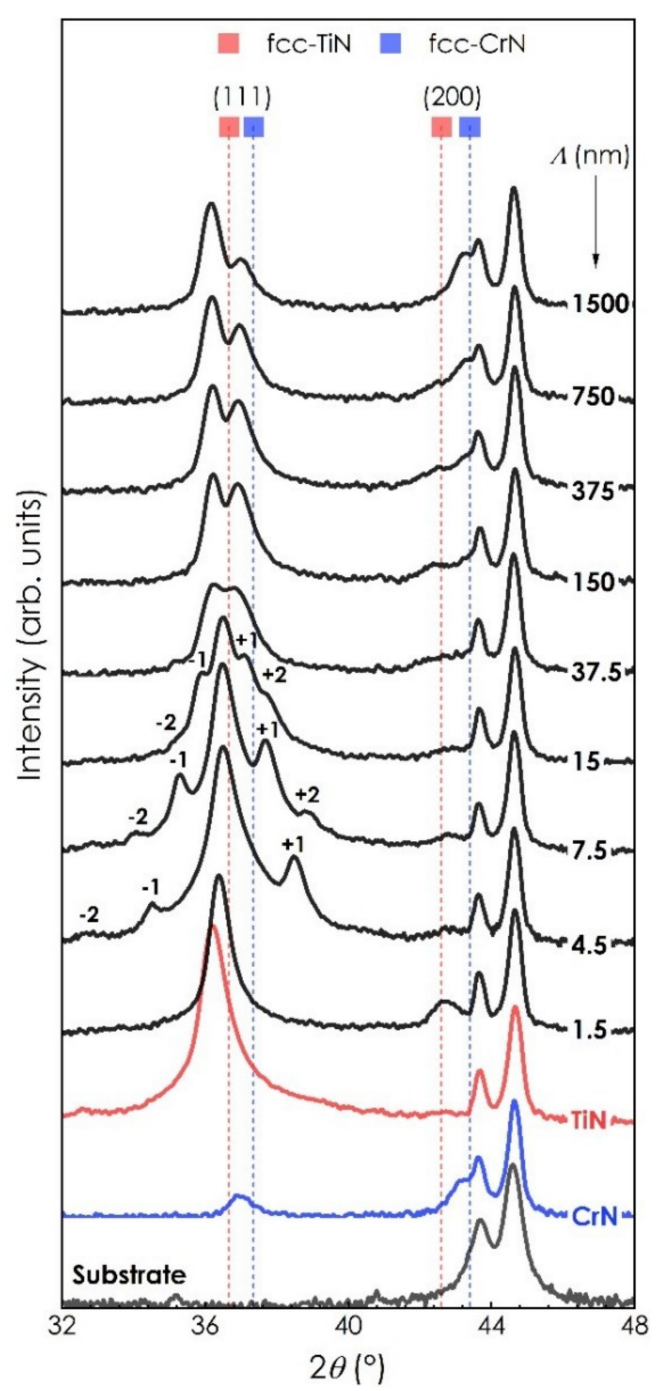

Figure 2. X-ray diffraction (XRD) patterns of TiN/CrN coatings with increasing bilayer period from bottom $(\Lambda=1.5 \mathrm{~nm})$ to top $(\Lambda=1500 \mathrm{~nm})$. The first three bottom diffractograms stem from the uncoated substrate, and binary monolithic $\mathrm{CrN}$ and TiN.

EDX analysis of TiN and $\mathrm{CrN}$ monolithic coatings carried out on three different spots on the surface close to both edges and in the middle reveals uniform distribution of the elements (see the errors bars in Figure 3). Moreover, EDX analysis also reveals superstoichiometry in all coatings (see Figure 3). Accordingly, $\mathrm{N}$ content in monolithic $\mathrm{CrN}$ was found to be 56 at.\%, even higher in monolithic TiN, namely 60 at.\%, while it was about 57 at. $\%$ in multilayer coatings $\mathrm{CrN} / \mathrm{TiN}$. Such a high concentration of nitrogen in $\mathrm{B} 1$ structured $\mathrm{CrN}$ and TiN might be directly related to the low deposition temperature [34]. In fact, superstoichiometry was observed in many earlier studies on TiN [35-38] and CrN [39] coatings deposited at low temperatures by means of magnetron sputtering. It is also worth mentioning that elemental composition in the referenced studies was determined by more reliable techniques, e.g., RBS [38] or AES [36]. According to the earlier first-principle calculations, superstoichiometric B1-CrN $(x>1)$ energetically prefers to form through the generation of metal vacancies and incorporation of nitrogen into the anti-sites rather than through incorporation of nitrogen into the interstitial sites [40]. Additionally, superstoichiometry might also be caused by excessive nitrogen at grain boundaries, since a high nitrogen-to-total-pressure ratio was used during all depositions [35]. 


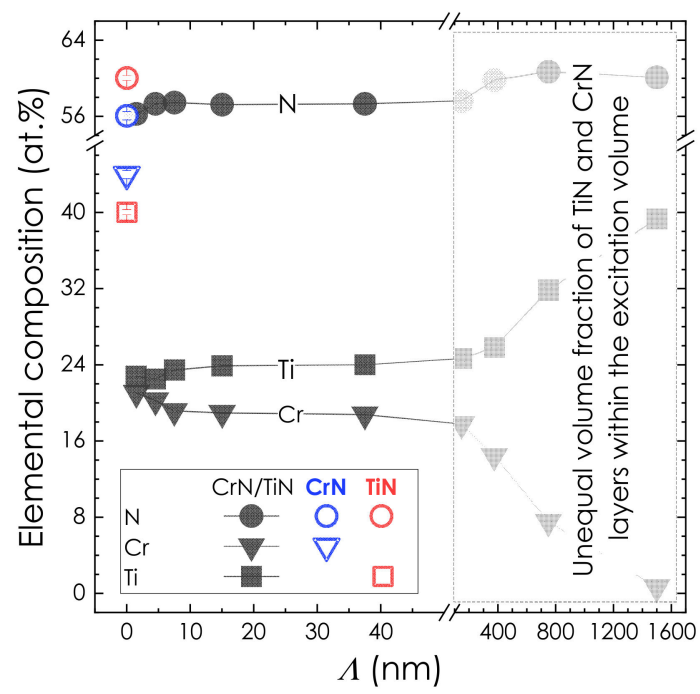

Figure 3. EDX analysis of all coatings studied. The area of large bilayer periods is shadowed since the penetration depth of the X-rays of a few hundred nanometers provides information about the top layer (TiN) to a higher extent the larger the bilayer period is. The error bars obtained for $\mathrm{CrN}$ (blue empty symbols) and TiN (red empty symbols) monolithic coatings represent standard deviation from the mean values resulted from the measurements on three different spots on the surface: in the middle and close to the edges.

\subsection{Mechanical Properties}

The results of nanoindentation tests show that TiN/CrN multilayer coatings exhibit the hardness values between that of binary $\mathrm{TiN}(36.7 \pm 1.8 \mathrm{GPa})$ and $\mathrm{CrN}(25.1 \pm 1.2 \mathrm{GPa})$ independent of bilayer period, see Figure 4a. However, bilayer period plays a crucial role in the hardness of TiN/CrN multilayer coatings. The highest hardness was $33.1 \pm 2.0 \mathrm{GPa}$ for the bilayer period of $7.5 \mathrm{~nm}$ (see Figure $4 \mathrm{a}$ ). According to the XRD investigations shown in Figure 2, such bilayer period results in the most pronounced superlattice structure as well.

With increasing bilayer period, indentation hardness of TiN/CrN multilayers decreases noticeably to $29.5 \pm 2.4 \mathrm{GPa}(\Lambda=37.5 \mathrm{~nm})$ and to $28.4 \pm 0.8 \mathrm{GPa}(\Lambda=150 \mathrm{~nm})$ but remains slightly above $28 \mathrm{GPa}$ with further $\Lambda$ increase up to $1500 \mathrm{~nm}$. Hardness decrease in TiN/CrN multilayers with increasing bilayer period can be associated with decreasing volume fraction of the interlayer interfaces and hence facilitation of dislocation propagation into the adjacent layers. Larger bilayer periods also allow the formation of larger grains, and hence provide a lower volume fraction of the grain boundaries. Accordingly, dislocation movement is less impeded.

At the same time, smaller bilayer periods also result in lower hardness values of the multilayer coatings, compare $32.1 \pm 2.2 \mathrm{GPa}(\Lambda=4.5 \mathrm{~nm})$ and to $31.9 \pm 1.8 \mathrm{GPa}(\Lambda=1.5 \mathrm{~nm})$. According to XRD analysis, the smaller $\Lambda$ is, the less pronounced the superlattice structure becomes and the more such multilayers tend to form a $(\mathrm{Ti}, \mathrm{Cr}) \mathrm{N}$ solid solution. This in turn leads to the loss of barrier properties possessed by multilayer structures.

The indentation modulus of TiN/CrN multilayer coatings shows a similar trend as indentation hardness and lays between $E$ values of binary TiN ( $427 \pm 14 \mathrm{GPa})$ and $\mathrm{CrN}(313 \pm 12 \mathrm{GPa})$ independent of bilayer period, see Figure $4 \mathrm{~b}$. However, indentation modulus peaks in the $E-\Lambda$ curve (showing $399 \pm 21 \mathrm{GPa}$ ) for a lower $\Lambda=4.5 \mathrm{~nm}$. With increasing bilayer period, indentation modulus of TiN/CrN multilayers decreases noticeably to $383 \pm 18 \mathrm{GPa}(\Lambda=7.5 \mathrm{~nm})$ and to $364 \pm 35 \mathrm{GPa}(\Lambda=15 \mathrm{~nm})$ but remains about $360 \mathrm{GPa}$ with further $\Lambda$ increase up to $1500 \mathrm{~nm}$. Similarly, smaller bilayer periods also result in lower indentation modulus of the multilayer coatings, compared with $381 \pm 12 \mathrm{GPa}$ $(\Lambda=1.5 \mathrm{~nm})$. 


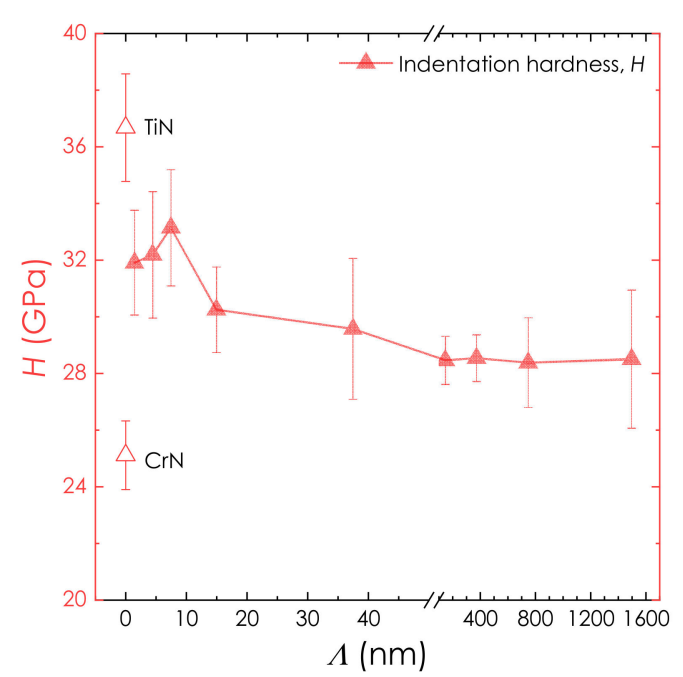

(a)

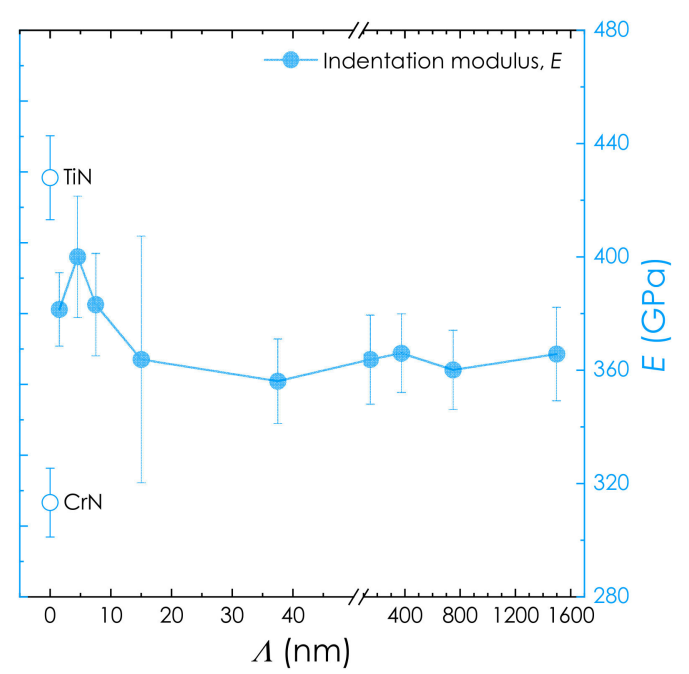

(b)

Figure 4. Indentation hardness $H(\mathbf{a})$ and modulus $E(\mathbf{b})$ of our TiN/CrN coatings as a function of their bilayer period.

\subsection{Fracture Investigation}

Cracking and deformation mechanics were observed after high-load indentations performed with a cube-corner indenter. After examination of the residual imprints via SEM, all of our multilayer coatings show similar patterns without radial cracks initiated on the imprint edges or blister area due to buckling, which is common for many PVD hard coatings with huge residual stresses [28].

High-magnification SEM (HMSEM) examination of the residual imprints made at loads $\leq 100 \mathrm{mN}$ suggests that no cracks could be generated in the multilayer coatings. This is furthermore supported by the continuous load-displacement curves and testifies to a high cohesive strength preventing the initiation of surface cracks caused by high bending tensile stress around the indenter. Since cracking is not a relevant mechanism to address the plastic deformation of the coatings at such loads and considering columnar structure of the coatings, grain sliding could be the major reason (see the discussion of the TEM investigations).

However, if higher loads are applied, HMSEM observations reveal circumferential cracks around the indent region with differences in radius and distribution depending on the loading level but also bilayer period of multilayers, see Figure 5. By increasing the load to $300 \mathrm{mN}$ and consequently increasing the bending tensile stress at the coating surface, surface cracks emerge and form the circumferential cracks around indent zone as shown in Figure $5 \mathrm{~b}$. Crack may propagate downward to the coating-substrate interface or deflect at the interlayers interface. Load-displacement curve reveals a pop-in at the load about $130 \mathrm{mN}$. According to previous studies [33,41], this plateau is related to the local delamination of the coating due to high lateral pressure (which can be used to quantitatively estimate apparent fracture toughness of the coatings). Upon further increase of the load, based on the toughness and buckling resistance of the delaminated area, second circumferential crack forms outside the first one. As soon as the second crack propagates completely downward to the interface, another plateau will appear in the load-displacement curve. Since we observe only one plateau in the load-displacement curve of each coating, there is only one crack completely propagated to the substrate and initiated coatings delamination.

For a better understanding of the fracture events, especially those at the coating-substrate interface, as well as investigation of second and third circumferential cracks and their correlation with structural properties, cross-sectional studies of the residual imprints were carried out by means of SEM. For this purpose, one half of the imprint was removed in a FIB milling process leaving the cross-section of the remaining area for investigations (see Figure 6). The cross-section in Figure $6 \mathrm{~b}$ elucidates the major fracture events, namely surface-initiated cracks, as well as coating-substrate interface delamination. 


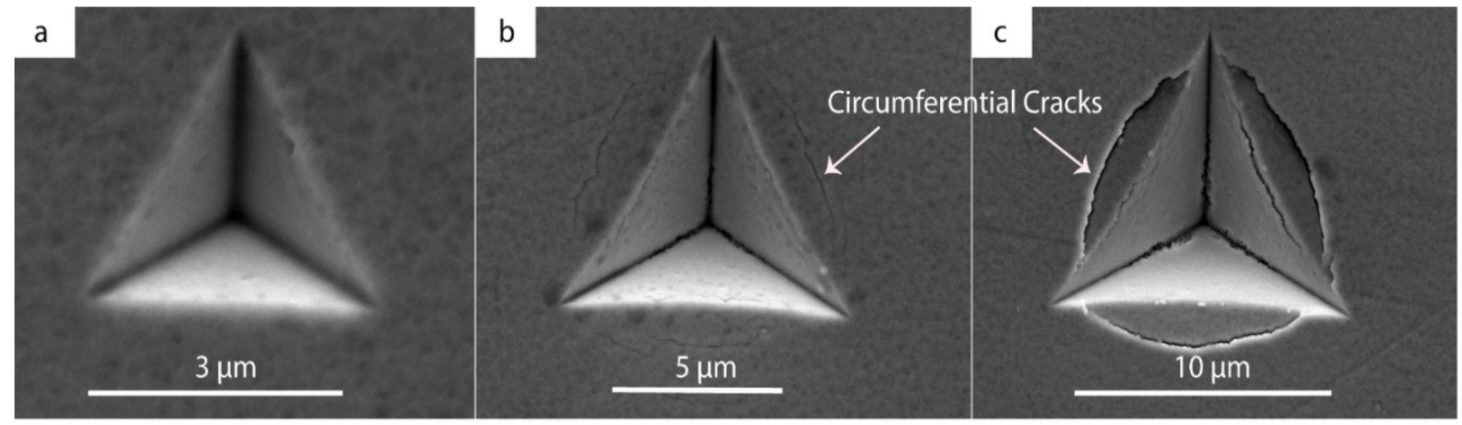

Figure 5. Residual imprints after indentation of the multilayer coating with $\Lambda=4.5 \mathrm{~nm}$ with a cube-corner indenter at 100 (a), 300 (b), and 450 (c) $\mathrm{mN}$.
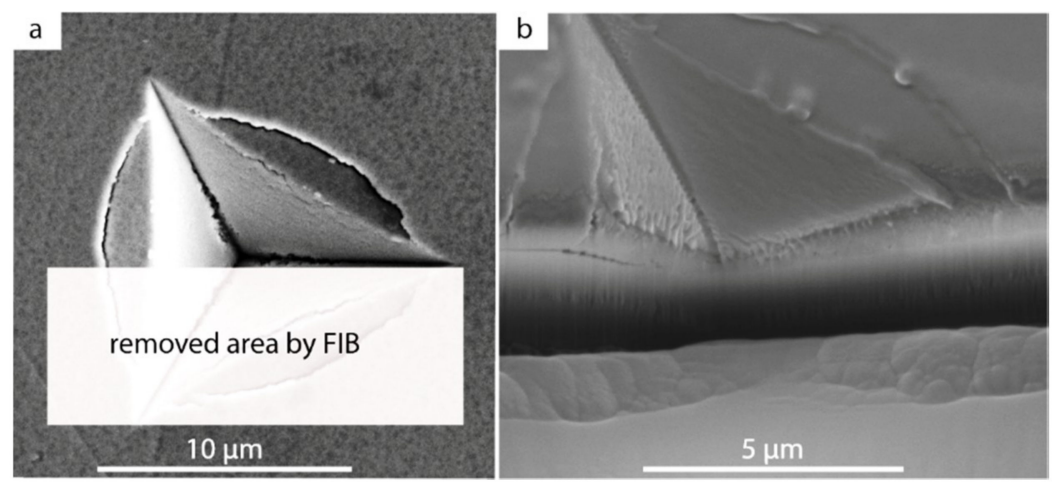

Figure 6. Schematic representation of the removed area by focused ion beam (FIB) (a) and cross-sectional scanning electron microscopy (SEM) image of milling channel (b) for the multilayer coatings with $\Lambda=4.5 \mathrm{~nm}$.

Based on the bilayer period, different cracking mechanisms can be observed in the multilayer coatings as revealed by the cross-sectional SEM investigations shown in Figure 7. These include circumferential cracks (CC), shear steps (SS), and interfacial cracking (IC) or delamination. Due to the presence of the columnar structure as well as layered configuration in the multilayer coatings, a complex combination of the deformation mechanisms occurs. Based on the generated stresses beneath and around the indenter, deformation behavior of the multilayer coatings can be divided into two regimes: compressive and tensile. As the indenter approaches the coating surface and pushes down the whole system, high compressive stress arises directly beneath the indenter which forces the columns to slide alongside each other producing shear steps. The required shear stress to initiate the column sliding depends mainly on the size and distribution of the columns as well as the number of the interlayer interfaces. By increasing the number of the interlayer interfaces (hence decreasing the bilayer period), additional barriers appear hindering the columns glide. Coatings with bilayer periods of 150 and $375 \mathrm{~nm}$ produce wider steps (Figure 7c,d), whilst the superlattice coating with $\Lambda=4.5 \mathrm{~nm}$ produces steps with a narrow width. Larger bilayer periods can ease the deformation process due to less interface barriers and smaller number of the grains. On the contrary, a higher number of the interlayer interfaces and grains requires more energy to activate columnar glide. Therefore, coatings with larger bilayer periods tend to deform by local shear sliding, while with smaller bilayer periods in the more slid areas. Accordingly, only small cracks are observed for the coatings with $\Lambda=150$ and $375 \mathrm{~nm}$, while circumferential cracks can be clearly seen for $\Lambda=4.5 \mathrm{~nm}$. 

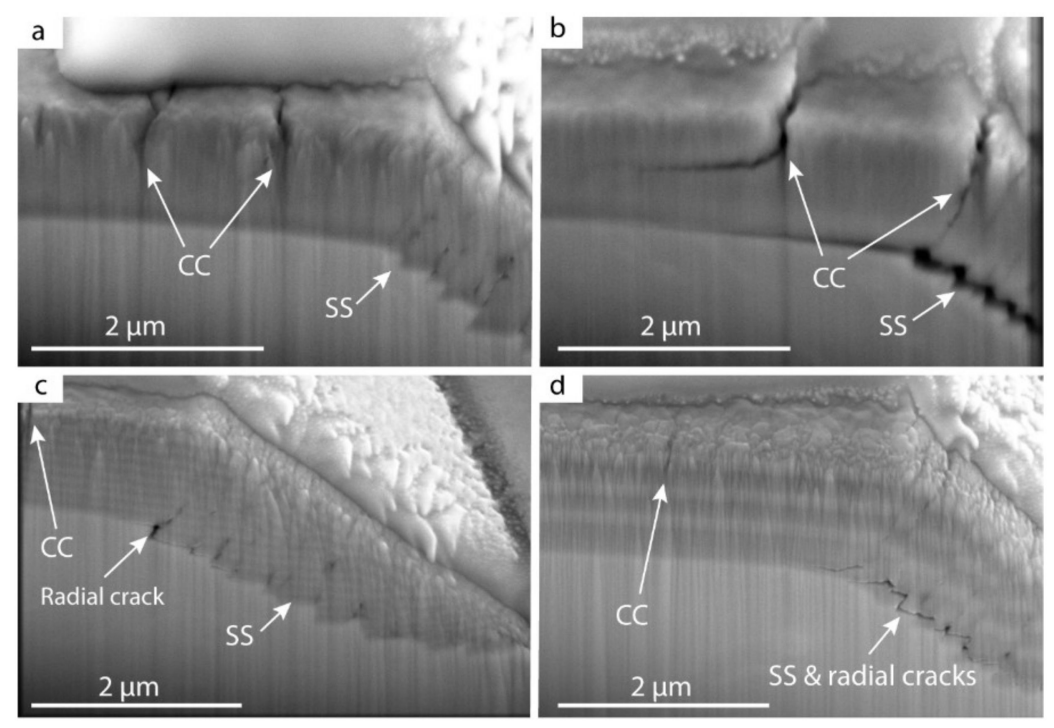

Figure 7. Scanning electron microscopy (SEM) images of focused ion beam (FIB)-exposed cross-sections of the multilayer coatings with $\Lambda=1.5$ (a), 4.5 (b), 150 (c), and 375 (d) $\mathrm{nm}$. The location of circumferential cracks (CC), shear steps (SS), and residual cracks is shown with the arrows.

Furthermore, in the first stages of loading with small displacement of the indenter, maximum tensile principal stress will be produced in the coating-substrate interface and then be expanded to the middle of the coatings [26,42]. Whenever sufficient principal stress arises at the coating-substrate interface, coatings with weaker column boundaries and wider shear steps are prone to generate the radial cracks caused by opening of the two adjacent steps (Figure 7c,d). Multilayer effect can play a major role in the propagation and growth path of the radial cracks towards the coating's surface. Radial cracks can be observed in Figure 7 for multilayer coatings with bilayer period of 1.5, 150, and $375 \mathrm{~nm}$, which indicates that after formation of the shear steps at the coating-substrate interface, these coatings become less resistant to the upward crack growth. However, these types of cracks are not obvious for the coating with $\Lambda=4.5 \mathrm{~nm}$ indicating that superlattice structure has a significant resistance against radial crack growth as compared to other multilayer coatings.

After increasing the load and consequently increasing the indenter penetration into the coating, bending tensile stress will be generated in the coatings' top layers around the indenter, producing the maximum tensile principal stress. In this stage, mentioned area of the coatings acts as a beam and surface cracks start forming circumferential cracks. Focusing on first and second circumferential cracks in Figure 7 presented by CC marks, it can be seen that the first crack is formed at the end of the indent zone for the coatings with the superlattice structure (e.g., $\Lambda=4.5 \mathrm{~nm}$ in Figure $7 \mathrm{~b}$ ), whilst for other multilayer coatings it is generated a little far away from the indentation edge. This might result from a higher amount of energy released through the shear steps and radial cracks in solid solutions (Figure 7a) and multilayers with significantly larger bilayer periods (Figure 7c,d) as compared to superlattices. Furthermore, consumed energy in shear steps will reduce the total work of the indenter and consequently maximum generated stress at the coating's surface will be decreased and shifted far off the indent zone. Therefore, the formation of the circumferential cracks for superlattice structures is faster than in other systems, which is also an indicator of the higher hardness and elastic properties, which is in line with the results of the nanoindentation measurements.

Once first circumferential cracking occurs, followed by the column glides under the indenter contact area, local delamination in the coating-substrate interface takes place and upon further increase of the indenter load, interfacial cracks grow up. In Figure 7b, directly under the first circumferential crack, delamination occurred and expanded to the larger areas. Because of the high elastic recovery of the superlattice coatings during unloading stage and spring-back effect of the system (showed by high elastic modulus obtained with nanoindentation tests), the delaminated area becomes more obvious. 
For coatings with larger bilayer periods, delamination happens due to the coalescence of the separate cracks induced by shear steps. (Interfacial cracks or delamination effects will be manifested as a plateau in the load-displacement curve.)

Another significant observation in the cross-sections of the residual imprints (see Figure 7) are the second circumferential cracks around the indent area. These second circumferential cracks are more pronounced for multilayer coatings with superlattice structures, which also show horizontally deflected path, while other multilayer systems demonstrate non-deflected growth path for second circumferential cracks. Crack deflection can in turn lengthen the propagation length and therefore increases the apparent fracture toughness. Hence, when multilayer coatings deform as a beam, surface cracks induced by high bending tensile stress represent different growth paths. Previous studies on the fracture investigations on the free-standing multilayer coatings, prepared as a single cantilever beam and subjected to bending loads, reveal improved fracture toughness for coatings with superlattice structures $[16,17,43]$.

As discussed above, the combination of various mechanisms in the tension and compression state of the overall stress induced in the multilayer coatings happens during general fracture of the system. In order to quantify the fracture investigations, plateau portions of the load-displacement curves for all multilayer coatings are analyzed. In Figure 8, plateau section of the loading curve is magnified for a better measurement of the required parameters. Once load reaches $F_{1}$ at the displacement $h_{1}$, a sudden jump of the indenter in the displacement caused by delamination of the coating induces a step in the curve, ending at the load $F_{2}$ and the corresponding displacement $h_{2}$. This step is an indication of the energy dissipated during fracture, $U$. At the absence of the cracking and delamination in the system, load-displacement behavior of the curve from $h_{1}$ to $h_{2}$ follows the red line in Figure 8 , resulting in $F_{3}$ in the displacement of $h_{2}$. The obtained area between the extrapolated red line and experimental green line and limited by the black curve represents the energy dissipated during the fracture. (Here, the black curve is a result of extrapolation of the unloading curve acquired at $100 \mathrm{mN}$, i.e., without steps, up to the intersection point with the red line). The calculated dissipated energy for the multilayer system with $\Lambda=4.5 \mathrm{~nm}$ has the maximum value implying the highest energy required for cracking activation and consequently toughness. It should be noted that obtained energy is the resultant of all mechanisms of absorption of the deformation energy, however, the cracking mechanism is predominant. Fracture energy decreases with increasing bilayer periods up to $200 \mathrm{~nm}$ but increases again with larger bilayer periods, see Figure 9 . This result is in accordance with previous studies $[16,17]$, indicating that the effect of a multilayer structure on cracking resistance is more dominant than shear sliding of the granular structure effect. The increase in dissipated energy for bilayer periods larger than $150 \mathrm{~nm}$ can be attributed to the relatively large TiN top layer dominating the fracture process. The resulting apparent fracture toughness can be calculated as follows:

$$
K_{\mathrm{c}}=\sqrt{\frac{E U}{\left(1-v^{2}\right) A}}
$$

Here, $E$ and $v$ are indentation modulus and Poisson's ratio of the coating, respectively [28]. A can be expressed as $A=2 \pi \cdot C_{\mathrm{R}} \cdot t$, where, $2 \pi \cdot C_{\mathrm{R}}$ is the crack length in the coating plane, $C_{\mathrm{R}}$ is the radius of circumferential through-thickness crack formed around the indenter, and $t$ is the coating thickness. The apparent fracture toughness of our multilayers follows the trend given by the dissipated energy. Due to the significant influence of the top TiN layer on the fracture toughness values for multilayer coatings with bilayer periods larger than $150 \mathrm{~nm}$, obtained values cannot be purely related to the multilayer system. Additionally, the right side of the Figure 9 representing the fracture energies for coatings with $\Lambda>150 \mathrm{~nm}$, is blurred. Summarized results are listed in Table 2. 


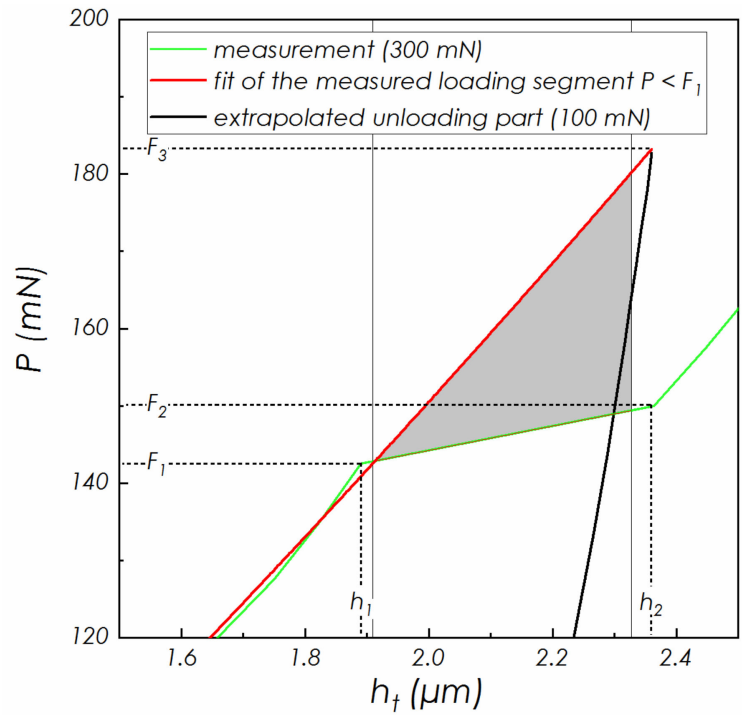

Figure 8. Schematic illustration of the plateau formed in the load-displacement curve and defined parameters.

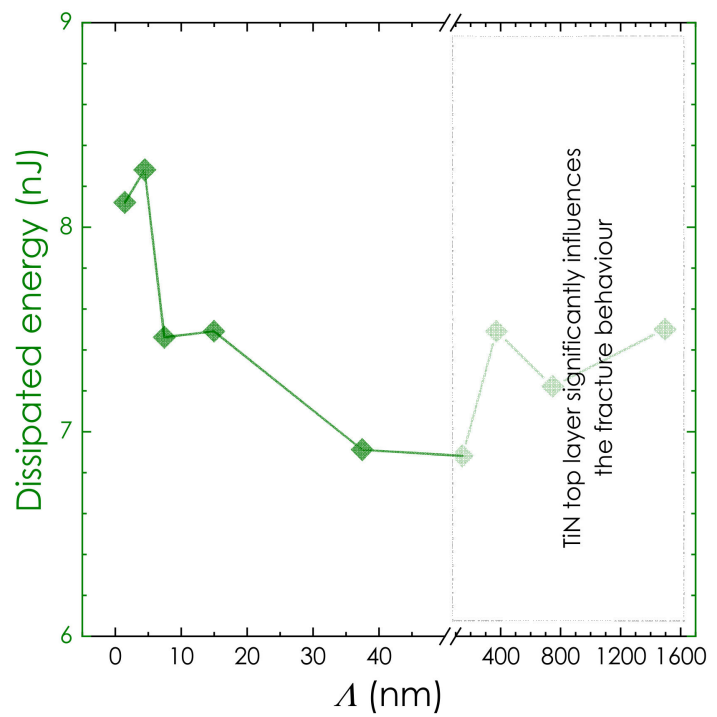

Figure 9. Dissipated energy dependence on the bilayer period for $\mathrm{CrN} / \mathrm{TiN}$ multilayer coatings.

Table 2. Summarized obtained data for toughness measurement of the multilayer coatings.

\begin{tabular}{ccccccccc}
\hline $\boldsymbol{\Lambda}(\mathbf{n m})$ & $\begin{array}{c}\text { Crack } \\
\text { Type }\end{array}$ & $\begin{array}{c}\text { Crack } \\
\text { Length } \\
(\mu \mathbf{m})\end{array}$ & $\boldsymbol{F}_{\mathbf{1}}(\mathbf{m N})$ & $\boldsymbol{F}_{\mathbf{2}}(\mathbf{m N})$ & $\boldsymbol{h}_{\mathbf{1}}(\boldsymbol{\mu m})$ & $\boldsymbol{h}_{\mathbf{2}}(\boldsymbol{\mu m})$ & $\begin{array}{c}\text { Dissipated } \\
\text { Energy } \\
(\mathbf{n J})\end{array}$ & $\begin{array}{c}\text { Apparent } \\
\text { Fracture } \\
\text { Toughness } \\
\mathbf{( M P a} \sqrt{\mathbf{m})}\end{array}$ \\
\hline 1.5 & CC, SS & 5.04 & 136.04 & 141.87 & 1.90 & 2.42 & 8.12 & 8.34 \\
4.5 & CC, SS & 4.82 & 127.39 & 134.63 & 1.88 & 2.39 & 8.28 & 8.82 \\
7.5 & CC, SS & 5.02 & 127.39 & 135.08 & 1.85 & 2.33 & 7.46 & 8.04 \\
15 & - & - & 127.39 & 135.59 & 1.90 & 2.39 & 7.49 & - \\
37.5 & CC, SS & 5.37 & 127.39 & 134.63 & 1.90 & 2.37 & 6.91 & 7.23 \\
150 & CC, SS & 5.58 & 127.39 & 135.08 & 1.89 & 2.37 & 6.88 & 7.01 \\
375 & IC, SS & 4.71 & 127.39 & 134.63 & 1.92 & 2.39 & 7.49 & 8.03 \\
750 & IC,SS & - & 127.39 & 135.59 & 1.89 & 2.39 & 7.22 & - \\
\hline
\end{tabular}




\subsection{TEM Investigations}

Cross-sectional TEM as well as STEM observations allow us to provide deeper insights into the deformation events in multilayer coatings with $\Lambda=4.5$ (with the most pronounced superlattice structure, Figure 10) and $150 \mathrm{~nm}$ (Figure 11) after indentation with a cube-corner indenter at $100 \mathrm{mN}$. Four shear steps on each side of the residual imprint in superlattice coating with $\Lambda=4.5 \mathrm{~nm}$ can clearly be observed in the cross-sectional STEM-HAADF image, see Figure 10a. This illustrates that columnar glide is the main deformation mechanism when applying indentation loads $\leq 100 \mathrm{mN}$. Selected Area Electron Diffraction (SAED) patterns of the three regions: "1" for area beneath the indenter tip, "2" for indented edge region and " 3 " for regions far away the indented zone; are shown in Figure 10b-d, respectively. All of the SAEDs represent intense diffraction ring in $<111>$ direction with discrete ring spots indicating the mostly regular distribution of grains. Due to high deformation under indenter and indented edge area, their patterns turn to more blurry spot rings, compared to those for un-deformed area (region " 3 "). Additionally, a bright-field image reveals continuous columns growing parallel to each other and though a high number of the layers (Figure 10e). It can be seen clearly that the shear steps are initiated along the large columns glide direction and continued directly to the coating-substrate interface without any deflection (see Figure 10f,g). By imposing more constraint and confinement against the columnar glide from the substrate in the coating-substrate interface, the gap between two adjacent steps can generate a radial crack. As loading increases, the number of steps also increases and interaction between increased number of the radial cracks and compressive stresses holding columns in contact causes interfacial delamination (see Figure $7 \mathrm{~b}$ ). The bright-field image of the near-surface area (marked " 4 " in Figure 10a) shows that beside the long columns glide line, short inclined glide line induced by smaller grains can be observed (see Figure 10f). Hence, though high compressive stresses generated in the contact area of the coatings directly beneath the indenter can also activate the glide movement of the smaller grain, their sliding line will be confined by the glide line of the longer columns. Layers configurations and deformed shape of the layers in the near-radial-cracks area are represented in the STEM-HAADF image in Figure 10h. Due to the small thickness of each layer as well as strong interlayers interfacial strength, deformation mechanisms like dislocation movement cannot occur inside the layers, and grain sliding of long columns is the main factor for coating's plastic deformation.

Unlike the coating with $\Lambda=4.5 \mathrm{~nm}$, no long sliding line through the entire coating can be observed in our $\mathrm{CrN} / \mathrm{TiN}$ multilayer coating with $\Lambda=150 \mathrm{~nm}$ after indentation with a cube-corner indenter at $100 \mathrm{mN}$, see a STEM-HAADF image of the indentation cross-section in Figure 11a. This implies the absence of the long columns growing through many layers. The number of the generated steps is lower, but the steps are wider than in superlattice coating with $\Lambda=4.5 \mathrm{~nm}$. In addition to radial cracks, median cracks can also be observed. Furthermore, SAED pattern of the coating far region from the indented zone is shown in Figure 11b. Compared to Figure 10d, the diffraction spot rings are blurrier demonstrate the existence of the dispersed grown columns. It can be also seen that in addition to intense $<111>$ diffraction ring, $<220>$ ring (main diffraction peak for $\mathrm{CrN}$ in $\mathrm{XRD}$ analysis) has a significant intensity which means both TiN and $\mathrm{CrN}$ layers have their own growing directions, leading to more irregularity in grain formation to be caused. Moreover, SAED rings would be blurrier in the deformed areas, as can be seen in Figure 11c,b. Unlike the long-grown columns in (Figure 10e), grains forming columns have dispersed distribution and a short length, see Figure 11e. As a result, whenever a sliding between two adjacent layers at the near-surface region happens, it will be extended to a short distance, not to the bottom surface of the coating. Furthermore, due to dispersed distribution of the columns, median cracks induced by grain sliding in the middle planes can grow when tensile stresses reach their critical value. 

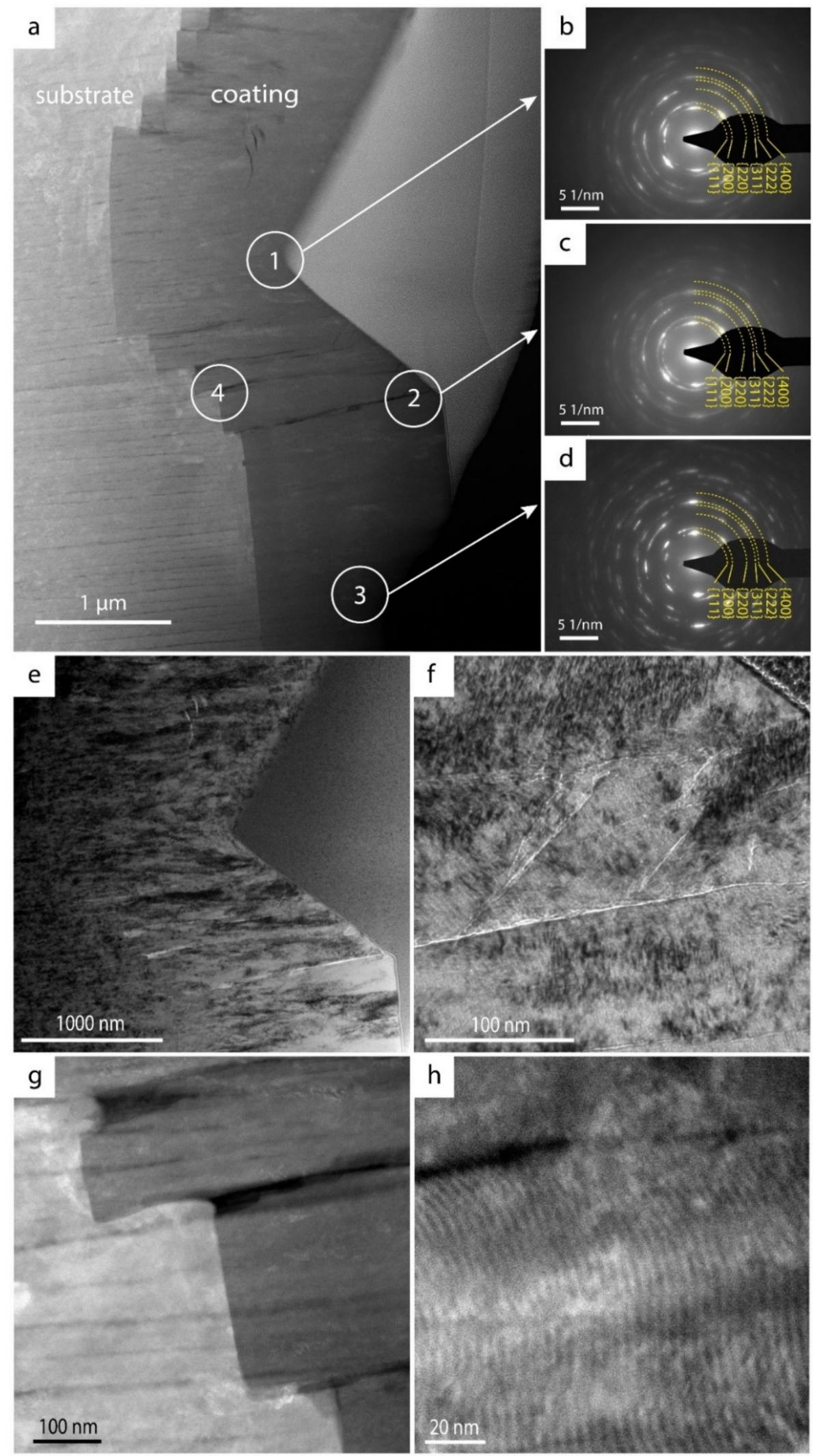

Figure 10. (a) overall high-angle annular dark field (HAADF) cross-sectional transmission electron microscopy (TEM) image of the superlattice with $\Lambda=4.5 \mathrm{~nm}$ after indentation with a cube-corner indenter at $100 \mathrm{mN}$. (b) SAED pattern in the region "1", (c) "2", (d) "3". (e) Bright field image of the indented region. (f) high-magnification bright field image of the region " 2 ", (g) STEM-HAADF image of the region " 4 ", and (h) high-magnification STEM-HAADF image of the layer configuration. 

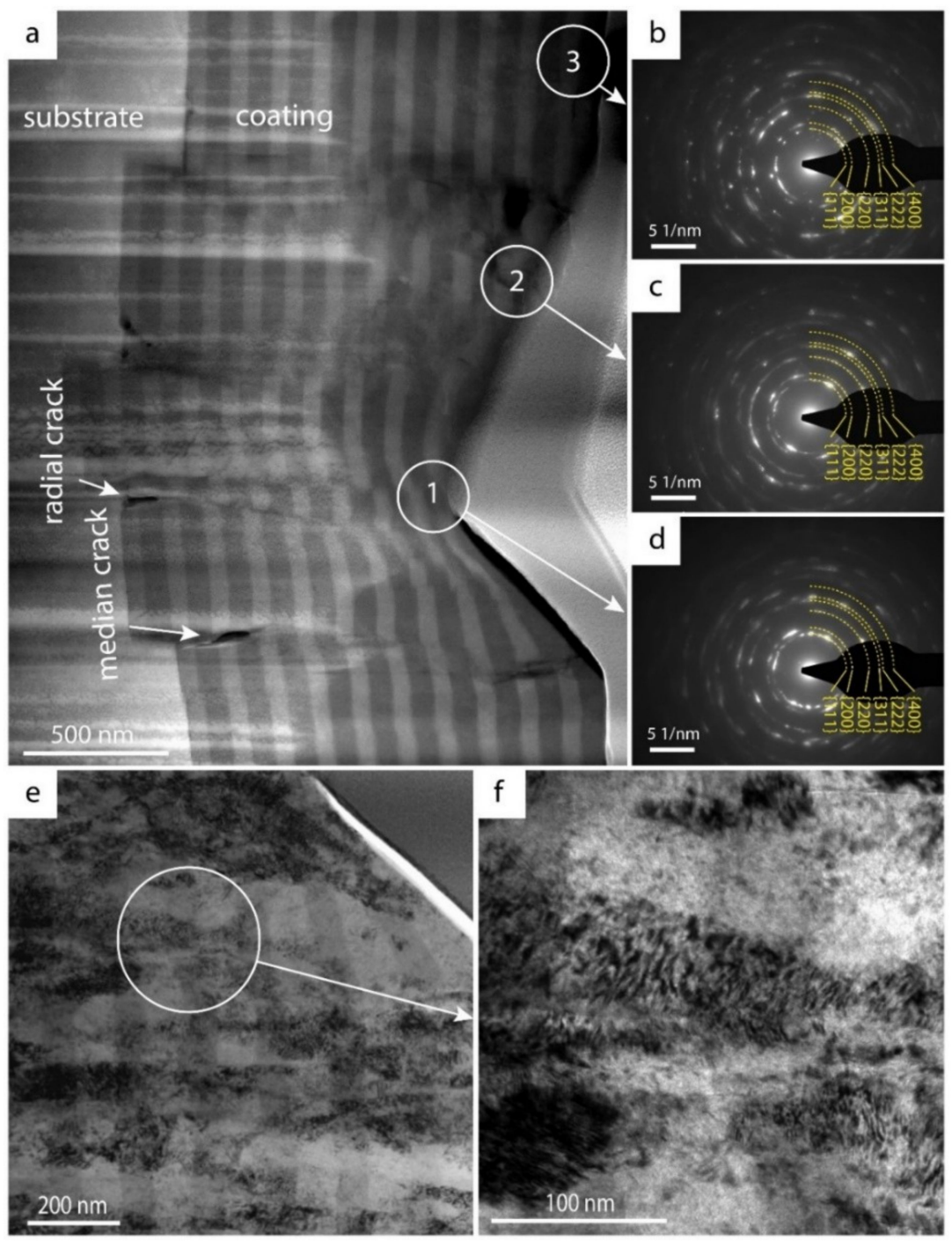

Figure 11. (a) Scanning transmission electron microscopy-high-angle annular dark field (STEM-HAADF) cross-sectional overview image of the multilayer coating with $\Lambda=150 \mathrm{~nm}$ after indentation with a cube-corner indenter at $100 \mathrm{mN}$, (b) SAED pattern in the region "1", (c) "2", (d) "3". (e) Bright field image of the near edge region. (f) high-magnification bright-field image of the circled area specified in $(\mathbf{e})$.

Individual layers and surrounded grains can be clearly identified at a higher magnification as shown in the bright-field image in Figure 11f. It can be seen that a grain is confined by four layers. Therefore, an inclination or rotation in the grain boundaries orientation caused by applied stresses deforms the layer alignment in the surrounding layers, as pushing down the $\mathrm{CrN}$ layer (darker layer) by downward motion of the grain causes a deflection in the layer. A higher number of the dispersed grains in the coatings with lager bilayer periods can hence absorb the energy of external work in the form of grain rotation and boundary grain sliding and consequently increase the energy needed for crack initiation and propagation. Therefore, plastic deformation of $\mathrm{CrN} / \mathrm{TiN}$ multilayer coatings at the indentation load of the $100 \mathrm{mN}$ could be explained based on the columnar sliding in the coatings with smaller bilayer period, and a combination of grain rotation and sliding of dispersed columns for higher the coatings with larger bilayer periods. Similar results were suggested in former works $[25,44]$. 


\section{Conclusions}

In this study, the cracking and deformation mechanisms of the $\mathrm{CrN} / \mathrm{TiN}$ multilayer coatings deposited on the GTD450 steel by reactive magnetron sputtering PVD method were investigated. All multilayered coatings were fabricated with the overall thickness of $1.5 \mu \mathrm{m}$ but different bilayer periods, $\Lambda$, of $1.5,4.5,7.5,15,37.5,150,375,750$, and $1500 \mathrm{~nm}$. XRD analysis revealed the (111) preferred growth and superlattice structure for multilayer coatings with $\Lambda$ in the range $4.5-15 \mathrm{~nm}$. The coatings with the superlattice structure exhibit the highest hardness values among all multilayer coatings. In particular, the bilayer period $\Lambda=7.5 \mathrm{~nm}$ (resulting in the most pronounced superlattice structure) endows the coating with the highest $H=33.1 \pm 2.0 \mathrm{GPa}$, significantly outperforming thus the multilayer coatings with $H$ slightly exceeding $28 \mathrm{GPa}$ independent of the bilayer period.

Cross-sectional SEM observations of the residual imprints (after indentation with a cube-corner indenter at $450 \mathrm{mN}$ ) revealed that in the compression area under the indenter-coating contact zone, columnar glide between adjacent long columns of superlattices produces several shear steps at the coating-substrate interface leading to interfacial delamination. However, pronounced shear sliding of the columns is not too obvious for multilayer coatings with $\Lambda>37.5 \mathrm{~nm}$ which produce fewer shear steps. Instead, radial and median cracks were observed for these multilayer coatings. Furthermore, circumferential surface cracks formed around the indent region (created by the high tensile stresses) showed different growth paths depending on the bilayer periods. For smaller bilayer periods $(\Lambda<37.5 \mathrm{~nm})$, crack deflection was observed, whilst at higher bilayer periods $(\Lambda>150 \mathrm{~nm})$ no deflection could be detected. Measurements of the dissipated energy during indentation based on the analysis of the load-displacement curves with pop-in effects showed that bilayer period and multilayer effect on apparent fracture toughness values are in accord with the results of earlier studies.

Cross-sectional TEM investigations of the residual imprints in our TiN/CrN coatings with $\Lambda=4.5$ and $150 \mathrm{~nm}$ made at $100 \mathrm{mN}$ provide deeper insights into the mechanism of plastic deformation of the coatings. Due to the long grown (111) columns in the multilayer coatings with smaller bilayer periods, particularly superlattice coatings, plastic deformation is mainly caused by column glide, instead of classical dislocation motions. However, short dispersed grains in the multilayer coatings with larger bilayer periods prevent the formation of the long sliding line of columns and deformation occurs by local grain boundary sliding between two layers and grains rotation.

Author Contributions: Conceptualization, A.A.; methodology, A.A., R.H. and F.F.K.; software, R.H., F.F.K. and T.W.; validation, A.A., R.H., F.F.K. and T.W.; investigation, A.A.; data curation, R.H., F.F.K.; writing-original draft preparation, A.A.; writing-review and editing, R.H., F.F.K., T.W., E.P. and P.H.M.; supervision, E.P. and P.H.M.

Funding: This research received no external funding.

Acknowledgments: Technical university of Vienna (TU Wien) and Institute of Materials Science and Technology are highly appreciated for providing XRD investigations using facilities of the XRC of TU Wien as well as, FIB, SEM and TEM observations at the USTEM of TU Wien, Austria.

Conflicts of Interest: The authors declare no conflict of interest.

\section{References}

1. Eklund, P.; Beckers, M.; Jansson, U.; Högberg, H.; Hultman, L. The $\mathrm{M}_{n+1} \mathrm{AX}$ 住 thin-film processing. Thin Solid Films 2010, 518, 1851-1878. [CrossRef]

2. Caicedo, J.C.; Amaya, C.; Yate, L.; Nos, O.; Gomez, M.E.; Prieto, P. Hard coating performance enhancement by using [Ti/TiN] $n,[\mathrm{Zr} / \mathrm{ZrN}] n$ and [TiN/ZrN] $n$ multilayer system. Mater. Sci. Eng. B 2010, 171, 56-61. [CrossRef]

3. An, T.; Wen, M.; Wang, L.L.; Hu, C.Q.; Tian, H.W.; Zheng, W.T. Structures, mechanical properties and thermal stability of $\mathrm{TiN} / \mathrm{SiN}_{x}$ multilayer coatings deposited by magnetron sputtering. J. Alloys Compd. 2009, 486, 515-520. [CrossRef]

4. Paulitsch, J.; Mayrhofer, P.H.; Münz, W.D.; Schenkel, M. Structure and mechanical properties of CrN/TiN multilayer coatings prepared by a combined HIPIMS/UBMS deposition technique. Thin Solid Films 2008, 517, 1239-1244. [CrossRef] 
5. Gilewicz, A.; Warcholinski, B. Tribological properties of $\mathrm{CrCN} / \mathrm{CrN}$ multilayer coatings. Tribol. Int. 2014, 80, 34-40. [CrossRef]

6. Klimashin, F.F.; Koutná, N.; Euchner, H.; Holec, D.; Mayrhofer, P.H. The impact of nitrogen content and vacancies on structure and mechanical properties of Mo-N thin films. J. Appl. Phys. 2016, 120, 185301. [CrossRef]

7. Bondar, O.V.; Postol'nyi, B.A.; Beresnev, V.M.; Abadias, G.; Chartier, P.; Sobol, O.V.; Kolesnikov, D.A.; Komarov, F.F.; Lisovenko, M.O.; Andreev, A.A. Composition, structure and tribotechnical properties of TiN, MoN single-layer and TiN/MoN multilayer coatings. J. Superhard Mater. 2015, 37, 27-38. [CrossRef]

8. Beresnev, V.M.; Bondar, O.V.; Postolnyi, B.O.; Lisovenko, M.O.; Abadias, G.; Chartier, P.; Kolesnikov, D.A.; Borisyuk, V.N.; Mukushev, B.A.; Zhollybekov, B.R.; et al. Comparison of tribological characteristics of nanostructured TiN, MoN, and TiN/MoN Arc-PVD coatings. J. Frict. Wear 2014, 35, 374-382. [CrossRef]

9. Rzepiejewska-Malyska, K.; Parlinska-Wojtan, M.; Wasmer, K.; Hejduk, K.; Michler, J. In-situ SEM indentation studies of the deformation mechanisms in TiN, CrN and TiN/CrN. Micron 2009, 40, 22-27. [CrossRef]

10. Roa, J.J.; Jiménez-Piqué, E.; Martínez, R.; Ramírez, G.; Tarragó, J.M.; Rodríguez, R.; Llanes, L. Contact damage and fracture micromechanisms of multilayered TiN/CrN coatings at micro- and nano-length scales. Thin Solid Films 2014, 571, 308-315. [CrossRef]

11. Paulitsch, J.; Schenkel, M.; Schintlmeister, A.; Hutter, H.; Mayrhofer, P.H. Low friction CrN/TiN multilayer coatings prepared by a hybrid high power impulse magnetron sputtering/DC magnetron sputtering deposition technique. Thin Solid Films 2010, 518, 5553-5557. [CrossRef]

12. Su, C.Y.; Pan, C.T.; Liou, T.P.; Chen, P.T.; Lin, C.K. Investigation of the microstructure and characterizations of TiN/CrN nanomultilayer deposited by unbalanced magnetron sputter process. Surf. Coat. Technol. 2008, 203, 657-660. [CrossRef]

13. Major, L.; Tirry, W.; Van Tendeloo, G. Microstructure and defect characterization at interfaces in TiN/CrN multilayer coatings. Surf. Coat. Technol. 2008, 202, 6075-6080. [CrossRef]

14. Steyera, P.; Megea, A.; Pecha, D.; Mendibidea, C.; Fontaineb, J.; Piersonc, J.-F.; Esnoufa, C.; Goudeaud, P. Influence of the nanostructuration of PVD hard TiN-based films on the durability of coated steel. Surf. Coat. Technol. 2007, 202, 2268-2277. [CrossRef]

15. Mendibide, C.; Steyer, P.; Fontaine, J.; Goudeau, P. Improvement of the tribological behaviour of PVD nanostratified TiN/CrN coatings-An explanation. Surf. Coat. Technol. 2006, 201, 4119-4124. [CrossRef]

16. Hahn, R.; Bartosik, M.; Arndt, M.; Polcik, P.; Mayrhofer, P.H. Annealing effect on the fracture toughness of CrN/TiN superlattices. Int. J. Refract. Met. Hard Mater. 2018, 71, 352-356. [CrossRef]

17. Hahn, R.; Bartosik, M.; Soler, R.; Kirchlechner, C.; Dehm, G.; Mayrhofer, P.H. Superlattice effect for enhanced fracture toughness of hard coatings. Scr. Mater. 2016, 124, 67-70. [CrossRef]

18. Stueber, M.; Holleck, H.; Leiste, H.; Seemann, K.; Ulrich, S.; Ziebert, C. Concepts for the design of advanced nanoscale PVD multilayer protective thin films. J. Alloys Compd. 2009, 483, 321-333. [CrossRef]

19. Bartosik, M.; Hahn, R.; Zhang, Z.L.; Ivanov, I.; Arndtd, M.; Polcike, P.; Mayrhoferab, P.H. Fracture toughness of Ti-Si-N thin films. Int. J. Refract. Met. Hard Mater. 2018, 72, 78-82. [CrossRef]

20. Bartosik, M.; Rumeau, C.; Hahn, R.; Zhang, Z.L.; Mayrhofer, P.H. Fracture toughness and structural evolution in the TiAlN system upon annealing. Sci. Rep. 2017, 7, 16476. [CrossRef]

21. Fuger, C.; Moraes, V.; Hahn, R.; Bolvardi, H.; Polcik, P.; Riedl, H.; Mayrhofer, P.H. Influence of Tantalum on phase stability and mechanical properties of $\mathrm{WB}_{2}$. MRS Commun. 2019, 9, 375-380. [CrossRef]

22. Ritchie, R.O. The conflicts between strength and toughness. Nat. Mater. 2011, 10, 817-822. [CrossRef] [PubMed]

23. Wang, Y.X.; Zhang, S. Toward hard yet tough ceramic coatings. Surf. Coat. Technol. 2014, 258, 1-16. [CrossRef]

24. Dehm, G.; Jaya, B.N.; Raghavan, R.; Kirchlechner, C. Overview on micro- and nanomechanical testing: New insights in interface plasticity and fracture at small length scales. Acta Mater. 2018, 142, 248-282. [CrossRef]

25. Kruppe, N.C.; Mayer, J.; Brögelmann, T.; Weirich, T.E.; Bobzin, K.; Arghavani, M. Plastic deformation behavior of nanostructured CrN/AIN multilayer coatings deposited by hybrid dcMS/HPPMS. Surf. Coat. Technol. 2017, 332, 253-261. [CrossRef]

26. Tilbrook, M.T.; Paton, D.J.; Xie, Z.; Hoffman, M. Microstructural effects on indentation failure mechanisms in TiN coatings: Finite element simulations. Acta Mater. 2007, 55, 2489-2501. [CrossRef] 
27. Bobzin, K.; Arghavani, M.; Weirich, T.E.; Mayer, J.; Brögelmann, T.; Kruppe, N.C. On the plastic deformation of chromium-based nitride hard coatings deposited by hybrid dcMS/HPPMS: A fundamental study using nanoscratch test. Surf. Coat. Technol. 2016, 308, 298-306. [CrossRef]

28. Zhang, S.; Zhang, X. Toughness evaluation of hard coatings and thin films. Thin Solid Films 2012, 520, 2375-2389. [CrossRef]

29. Oliver, W.; Pharr, G.M. Measurement of hardness and elastic modulus by instrumented indentation: Advances in understanding and refinements to methodology. J. Mater. Res. 2005, 19, 3-20. [CrossRef]

30. Klimashin, F.F.; Materialia, P.H. Ab initio-guided development of super-hard Mo-Al-Cr-N coatings. Scr. Mater. 2017, 140, 27-30. [CrossRef]

31. Fischer-Cripps, A.C. Critical review of analysis and interpretation of nanoindentation test data. Surf. Coat. Technol. 2006, 200, 4153-4165. [CrossRef]

32. Klimashin, F.F.; Riedl, H.; Primetzhofer, D.; Paulitsch, J.; Mayrhofer, P.H. Composition driven phase evolution and mechanical properties of Mo-Cr-N hard coatings. J. Appl. Phys. 2015, 118, 25305. [CrossRef]

33. Chen, J.; Bull, S.J. Modelling the limits of coating toughness in brittle coated systems. Thin Solid Films 2009, 517, 2945-2952. [CrossRef]

34. Gogotsi, Y.G.; Andrievski, R.A. Materials Science of Carbides, Nitrides and Borides; Springer: Dordrecht, The Netherlands, 2011.

35. Lemperière, G.; Poitevin, J.M. Influence of the nitrogen partial pressure on the properties of d.c.-sputtered titanium and titanium nitride films. Thin Solid Films 1984, 111, 339-349. [CrossRef]

36. Adjaottor, A.A.; Meletis, E.I.; Logothetidis, S.; Alexandrou, I.; Kokkou, S. Effect of substrate bias on sputter-deposited $\mathrm{TiC}_{x}, \mathrm{TiN}_{y}$ and $\mathrm{TiC}_{x} \mathrm{~N}_{y}$ thin films. Surf. Coat. Technol. 1995, 76-77, 142-148. [CrossRef]

37. Penilla, E.; Wang, J. Pressure and temperature effects on stoichiometry and microstructure of nitrogen-rich TiN thin films synthesized via reactive magnetron DC-sputtering. J. Nanomater. 2008, 2008, 267161. [CrossRef]

38. Ohya, S.; Chiaro, B.; Megrant, A.; Neill, C.; Barends, R.; Chen, Y.; Kelly, J.; Low, D.; Mutus, J.; O’Malley, P.J.J.; et al. Room temperature deposition of sputtered TiN films for superconducting coplanar waveguide resonators. Supercond. Sci. Technol. 2014, 27, 15009. [CrossRef]

39. Martinez, E.; Sanjines, R.; Banakh, O.; Lévy, F. Electrical, optical and mechanical properties of sputtered $\mathrm{CrN}_{y}$ and $\mathrm{Cr}_{1-x} \mathrm{Si}_{x} \mathrm{~N}_{1.02}$ thin films. Thin Solid Films 2004, 447-448, 332-336. [CrossRef]

40. Holec, D.; Zhou, L.; Zhang, Z.; Mayrhofer, P.H. Impact of point defects on the electronic structure of paramagnetic CrN. arXiv, 2014; arXiv:1410.0758v2. Available online: https://arxiv.org/abs/1410.0758(accessed on 31 May 2019).

41. Michel, M.D.; Muhlen, L.V.; Achete, C.A.; Lepienski, C.M. Fracture toughness, hardness and elastic modulus of hydrogenated amorphous carbon films deposited by chemical vapor deposition. Thin Solid Films 2006, 496, 481-488. [CrossRef]

42. Azizpour, A.; Poursaeidi, E. Fracture and deformation mechanism of Ti(C,N)/TiAlSiN multilayer coating: FE modeling and experiments. Ceram. Int. 2017, 43, 1830-1838. [CrossRef]

43. Llanes, L.; Roa, J.; Lamelas, V.; Rodríguez, R.; Martínez, R.; Jiménez-Piqué, E. Small scale fracture behaviour of multilayer TiN/CrN systems: Assessment of bilayer thickness effects by means of ex-situ tests on FIB-milled micro-cantilevers. Surf. Coat. Technol. 2016, 308, 414-417. [CrossRef]

44. Li, W.; Chen, X.; Liu, P.; Zheng, K.; Ma, F.; Liu, X. Investigation on microstructure and properties of CrAlN/AlON nanomultilayers. Appl. Surf. Sci. 2011, 257, 9583-9586. [CrossRef]

(C) 2019 by the authors. Licensee MDPI, Basel, Switzerland. This article is an open access article distributed under the terms and conditions of the Creative Commons Attribution (CC BY) license (http://creativecommons.org/licenses/by/4.0/). 